3. Байжуманова Н. К. К вопросу о промыслах в хозяйственном укладе кумандинцев предгорного Алтая в конце XIX - начале XX вв. // Этнография Алтая и сопредельных территорий : матер. междунар. науч.-практ. конф. (Барнаул, 29-30 сент. 2005 г.) - Барнаул : Изд-во Барнаульского гос. пед. ун-та, 2005. С. 70-71.

4. Карасева, Н. К. Бортничество кумандинцев предгорного Алтая в конце XIX-начале ХХ вв. // Фундаментальные исследования. - 2007. - № 8. - С. 1-5.

5. Кухтуекова, Н. В. Природные и социальные условия формирования и возрождения малочисленного этноса Сибири - кумандинцев // Социосфера. - 2013. - № 10. - С. 175-177.

Svetlana I. Bondarenko, Ph. D. in History, Associate Professor Altai State Agrarian University (Russia, Barnaul) bonsvet@bk.ru

\title{
ECONOMIC AND CULTURAL TRADITIONS OF KUMANDINS OF PIEDMONT ALTAI IN NIKOLAI SHERR'S WORKS
}

\begin{abstract}
The paper outlines some aspects of economic and cultural traditions of Kumandins who are one of indigenous people of Russia that is referred with North Altaians who fall under Turkic ethnic and linguistic community. The author of the article by using ethnographic writings made by Nukolai Sherr (1867?), a Russian political deportee and a researcher, describes basic elements of Kumandins of the $19^{\text {th }}$ and $20^{\text {th }}$ century, such as dwelling, food, clothes, names peculiarities of farming, gathering, cattle breeding, hunting, and highlights the next specifics of Kumandins' economic culture: dominance of harvesting, weak farming,. On Nikolai Sherr's notice, Russian settlers had a big effect of development of Kumandins' economic traditions.
\end{abstract}

Keywords: Kumandins, ethnography of Kumandins, North Altaians, Altai, traditions, culture, Nikolai Sherr, economic culture, catching, trading, food, vegetable gardening, beliefs.

УДК 72:[338.486:711.2]

DOI: $10.32340 / 2414-9101-2020-4-38-44$

Ю. С. Ананьева, кандидат химических наук Алтайский государственный педагогический университет (Барнаул, Россия) isan1963@yandex.ru

А. Г. Жаркова

Алтайский государственный технический университет им. И. И. Ползунова (Барнаул, Россия) madsheart@gmail.com

\section{АРХИТЕКТУРНЫЕ КОПИИ И ИСТОРИКО-КУЛЬТУРНЫЕ СТИЛИЗАЦИИ В ТУРИСТИЧЕСКОЙ СФЕРЕ}

\begin{abstract}
Аннотация. Рассмотрен состав факторов, определяющих возросшую популярность практик репликации архитектурных объектов, относящихся к категории памятников национального и мирового исторического и культурного наследия и привлекающих в этом качестве неизменный интерес потребителей услуг туристической сферы. В подтверждение своей точки зрения авторы ссылаются на многочисленные отечественные и зарубежные примеры создания копий приобретших всемирную известность сооружений, с разной степенью достоверности воплощающих характерные для архитектурных традиций той или иной культуры композиционные приёмы, художественные стили и декоративные мотивы. Кратко рассмотрены основные тенденции тиражирования архитектурных образцов традиционных культур в контексте инфраструктурного развития отечественных туристических локаций; изложены базовые аргументы сторонников и противников этого направления развития туристического сектора.
\end{abstract}


Ключевые слова: туризм, архитектура, артефакт, памятник, копия, историко-культурная стилизация, культурная глобализаџия.

Современные тенденции развития архитектуры в туристической сфере сложны и многообразны. Одним из интересных феноменов данного сектора является растущая тенденция создания архитектурных историко-культурных стилизаций и копий памятников мирового культурного наследия, в том числе архитектурных памятников и комплексов, относящихся к отдельным этнокультурным традициям. Это явление в последние годы приобрело популярность в различных странах мира, в том числе и в России. При этом отношение к указанной тенденции носит противоречивый характер, включая спектр мнений, расположенных между критическим и вполне одобрительным взглядом на данный феномен.

Среди причин указанного явления можно назвать фактор разрастания самой туристической отрасли и проблему привлечения туристов в регионы со слабым либо нереализованным в полной мере (что бывает довольно часто) собственным туристическим потенциалом. Вышеназванные практики призваны привлечь туристов и заинтересовать их. По сути, указанная тенденция носит исключительно развлекающий характер, сопровождаемый удивлением от неожиданно возникающих архитектурных копий или аллюзий на определенную историко-культурную тему. Эйфелева башня в России или Собор Василия Блаженного в Китае, несомненно, оказывают определенный эффект на потребителя туристической отрасли.

Еще одним фактором, воздействующим на распространение изучаемого феномена, является стандартизация и стереотипизация туристической отрасли, во многом провоцируемая процессами глобализации. Смешение устойчивых образов мирового культурного наследия в современной массовой культуре образует своеобразное «ризоматичное сочетание», составляющее усредненный набор легко узнаваемых образов и брендов различных культур. «Игра» с такими образами, их узнавание в неожиданном контексте нередко приносит удовольствие массовому потребителю [1, с. 4873], в том числе и туристу, подтверждая уровень его самодостаточности и историко-культурной осведомленности.

Примечательно, что на современном этапе одной из тенденций развития туризма, связанной со стандартизацией и смешением различных компонент данной сферы, стал феномен прямого и стилизованного тиражирования объектов туристического показа и обслуживания в виде неких усредненных «матриц», в частности репликацией американских и европейских развлекательных туристических комплексов, этно-, эко-, сафари парков, горнолыжных курортов, Диснейлендов и пр. Во многом реализацией указанных репликаций стали такие рекреационные территории, как Сочи-парк, «Дримвуд» в Крыму, «Диво-остров» в Санкт-Петербурге, Юркин парк в Казани, Бирюзовая Катунь в Горном Алтае, Кудыкина гора в Липецкой области, адаптированные под российского потребителя. Также в качестве примера можно привести горнолыжные курорты: «Большой Вудъявр», или «BigWood» возле Кировска; «Шерегеш» в Горной Шории; «Горный воздух» в Южно-Сахалинске; «Красная Поляна» и «Роза Хутор» в Сочи; курорт «Бобровый лог» в Красноярске; «Гора Соболиная» на Байкале; курорты Южного Урала, организаторы которых порой стремятся создать стилистические аналоги ведущих зарубежных курортов, например, «Куршевеля» во Франции. Вполне естественно, что при указанном экспорте, глобализации и стандартизации туристических практик, распространение получает и практика тиражирования образов и форм объектов мирового культурного наследия, дающая возможность посетителю определенной туристической локации увидеть 7 чудес света, побывать в Большом каньоне, на Великой китайской стене, в Тадж-Махале и т. п.

Еще одна причина роста указанного явления выражена в поиске новых приемов организации современных туристических локаций, что во многом свидетельствует о кризисе отрасли, в первую очередь призванной позиционировать изначальный потенциал туристических мест, а не использовать их для строительства архитектурных копий и стилизаций. Указанный феномен способствует, скорее, не продвижению мест, где они реплицируются, а во многом отражает постмодернистские 
характеристики культуры, выраженные в смешении разнородного, образовании «складок» в сознании, играми с контекстом, опровержением канонов, традиций, и т. п.

Кроме того, необходимо отметить, что на современном этапе одной из тенденций развития туризма, связанной с включением архитектурных копий и историко-культурных аллюзий в туристический кластер, является популяризация туристического направления, призванного «погружать» потребителя в определенную историко-культурную эпоху, стиль, образ жизни, в том числе и этнокультурную среду. Дело в том, что многие памятники мирового культурного наследия буквально «поглощены» и окружены более поздними наслоениями истории, что во многом затрудняет их восприятие как части определенного ландшафта и контекста. В результате популярность получают реконструированные в схожем ландшафте памятники и населенные пункты, этно-деревни и парки, целью которых является создание особой «ауры», «аромата подлинности» исторической эпохи, в которую предлагается отправиться туристу.

Наконец, следует отметить экономическую привлекательность указанного рода практик, которые могут реализовываться во многом с опорой на туристов, не имеющих возможности купить тур в определенное направление в силу дороговизны. В результате, отрасль предлагает «аналогичные» недорогие пути соприкосновения со многими мировыми достопримечательностями, пусть даже в их имитациях.

Обзор факторов, воздействующих на популяризацию рассматриваемого явления, можно продолжить, однако названного вполне достаточно, чтобы показать его устойчивость и высокую степень популярности.

Среди характерных примеров копий архитектурных памятников мирового значения можно выделить многократно растиражированный популярный туристический объект - Эйфелеву башню; ее копии можно увидеть, например, в Абакане, Пскове, Ижевске, а также в селе Париж Нагайбакского района Челябинской области. Среди зарубежных назовем многочисленные «новоделы» в китайском городе Маньчжурия (в числе которых копии собора Василия Блаженного и памятника «Рабочий и колхозница») и новоделы в Памуккале (Турция).

Особенно отличаются в этой связи воплощения изучаемых практик в КНР. Так, в Китае можно встретить Тауэрский мост в г. Сучжоу; Афинский Парфенон в г. Ланьчжоу; Эйфелеву башню в г. Тиандученг; Сиднейский Оперный театр, Белый дом и статуи Моаи в Пекине; Римский Колизей в Макао; Большого Сфинкса в г. Чучжоу; пирамиду Лувра в г. Чунцин; Карнакский храм в г. Вухан; Пизанскую башню в г. Шанхай; и многие другие достопримечательности. Примечательно, что «китайцы собираются построить копию «Титаника» в натуральную величину» [2].

Одним из ярких примеров воплощения рассматриваемых практик является тематический парк «Окно в мир» площадью 480000 квадратных метров, созданный в курортном китайском городе Шеньчжень. На обширной территории разместились все мировые достопримечательности. Восемь тематических зон посвящены Азии, Африке, Америке, Европе, Океании; среди объектов также есть Площадь мира, Международная улица и Парк скульптур. Желающие могут побродить вокруг уменьшенной копии Сиднейской оперы, поплавать по каналам Венеции, оценить величие Парфенона, есть даже Кремль и мини-мавзолей Ленина... Словом, любой памятник к вашим услугам. Остается вопрос лишь к качеству репродукций, которые, во-первых, уменьшены, а во-вторых, всётаки интереснее смотреть на оригинал, вписанный в контекст истории и места.

Отдельный интерес в рассматриваемом вопросе представляет то, что многие копируемые и стилизуемые в настоящее время шедевры мировой архитектуры сами содержат определенные элементы заимствования и стилизаций. Более того, будучи созданными на основе определенных прототипов, такие шедевры копировались и реплицировались в дальнейшем при создании поздних шедевров.

Например, у знаменитой Чесменской церкви Иоанна Предтечи - ее Ю. Фельтен построил в 1780 г. - было сразу две реплики. Одна из них - Спасо-Преображенская церковь в селе Красном, которое принадлежало в те годы дворянскому роду Полторацких. Доподлинно неизвестно, занимался ли ее строительством сам Фельтен, или же здание возводили просто по его чертежам. В лю- 
бом случае некоторые архитектурные детали интерпретированы довольно вольно: стрельчатый орнамент фасадов более витиеватый по сравнению с Чесменской церковью; в декоре использован местный белый камень, в то время как в оригинале скульптурные детали изготовлены из гипса. Также в Преображенской церкви сделано сразу три входа, хотя в Чесменской был всего один. У рассматриваемого храма было еще одно повторение - Никольская церковь в селе Посадниково Псковской области. Церковь построили по указу фаворита Екатерины II Александра Ланского. В целом архитектурные детали храма совпадали с его петербургским прототипом. Главное отличие - колокольня, которую построили рядом: в ансамбле Чесменской церкви ее не было. До сегодняшнего дня сохранились лишь фотографии Никольской церкви в селе Посадниково: в 1920-е гг. она была разрушена.

Другим примером является церковь Козьмы и Дамиана на Маросейке, построенная в 17911793 гг. по проекту Матвея Казакова. Средства на ее возведение выделил владелец соседнего дома - Михаил Хлебников. Казаков придумал необычную планировку церкви: храм состоял из четырех помещений в форме цилиндра: основного пространства церкви, апсиды (алтарной части) и двух боковых приделов. С западной стороны находились трапезная и колокольня. В дальнейшем храм с таким необычным планом повторяли не раз. Одна из ее реплик находится в Рязанской области - это Спасская церковь в Протасьевском углу. Композиция храма полностью повторяет московскую церковь: те же равные по размерам апсида и приделы. Сегодня церковь нуждается в реставрации. Однако, пока искусствоведы не могут доказать, что ее также построил сам Матвей Казаков, восстановление откладывается. Другая копия церкви на Маросейке - Никольская - находится в подмосковном селе Карачарово. Храм построили по указу графа Льва Разумовского. Его архитектура в точности повторяет московский храм Козьмы и Дамиана, так что строительство церкви также приписывают Матвею Казакову. К сожалению, на сегодняшний день состояние храма близко к разрушению.

Интересным примером рассматриваемых репликаций является уменьшенная копия храма Христа Спасителя - собор Рождества Пресвятой Богородицы в Ростове-на-Дону, построенная по проекту К. Тона. Ростовский храм отличался от московского прототипа колокольней: здание в четыре яруса высотой 75 метров построили рядом с церковью. В 1932 г. церковь была закрыта: кресты с куполов сняли, иконостас разобрали, все внутреннее убранство было утрачено. Внутри храма разместили склад, а затем зверинец. Однако уже в 1942 г. церковь снова открыли для богослужений. Кроме того, К. Тон стал автором двух идентичных зданий вокзалов: Московского вокзала в Петербурге и Николаевского в Москве - позже его переименовали в Ленинградский.

В данном случае актуальным становится вопрос - Где грань между копированием и созданием собственного детища? По этому вопросу признанные мастера архитектуры занимают разные точки зрения. Одни категорически против заимствования, другие считают это необходимым, третьи уверены, что копирование - обязательный этап в понимании фундаментальных законов архитектуры, только на основе которых можно создать новое и современное. Будет ли считаться недавно построенный замок неудачной интерпретацией из истории, или всё-таки это новый виток в архитектурном понимании стилизации под определенную эпоху?..

Возвращаясь к основной линии исследования, отметим, что в сфере рассматриваемых практик довольно часто речь идет не о точном или примерном копировании конкретных памятников, а об историко-культурных стилизациях под некую эпоху или конкретный памятник, например, о подстраивании под бытующие в массовом сознании усредненные представления о том, как должен выглядеть средневековый замок. Примеров подобных историко-культурных стилизаций, отражающих определенные стереотипы, ожидаемые и усредненные образы, многовсречаемы. В городе Сатка Челябинской области на берегу Заводского пруда находится аквапарк «Сонькина лагуна». Развлекательный комплекс стилизован под средневековые замки с пиратскими кораблями. Здесь можно с головой погрузиться в «эпоху Джека Воробья» и почувствовать себя частью того времени, погулять по висячему мосту, заглянуть в таверну «Бешеный Бен», сесть на корабль и отправиться на настоящий остров. Другим примером является Шато Эркен-замок в романском стиле в Кабардино- 
Балкарии, расположенный посредине озера и являющийся одновременно туристической локацией и винопроизводящим предприятием. В архитектуре замка преобладают лаконичные и простые геометрические формы, что позволяет ему полностью слиться с местным ландшафтом. Также уместно указать на неоготический замок Гарибальди - уникальный архитектурный комплекс в Самарской области, оформленный в духе традиций архитектуры средневековья, Ренессанса и Викторианской эпохи. Также интерес представляет сафари-парк «Кудыкина гора», расположенный на берегу Дона в Липецкой области. В парке есть множество арт-объектов и деревянных скульптур; по древним чертежам и без использования гвоздей построена «скифская» крепость, предназначенная для экспозиций и торговли сувенирами. В крепости планируется создание города мастеров, в котором умельцы будут демонстрировать свои таланты. Помимо названных примеров обращает на себя внимание база отдыха «Корона Алтая» - гостиничный комплекс, находящийся на острове Пихтовый посреди реки Катуни и стилизованный под средневековый замок, увенчанный короной. Попасть на остров можно только через подвесной мост.

Тем не менее, некоторые стилизации и реплики (нередко содержащие элементы китча), как правило, располагаясь довольно далеко от ареалов распространения соответствующих культур и лишаясь должного контекста, зачастую выглядят удивительными и странными, - особенно если регионы, воспроизводящие феномены других культур и исторических эпох, обладают собственным историко-культурным потенциалом.

Относительно вопроса копирования и стилизаций архитектурных памятников и комплексов, относящихся к отдельным этнокультурным традициям, необходимо указать, что в основе данного явления лежат те же факторы, что были названы выше, в отношении общемировых тенденций. В качестве примера использования таких практик можно отметить наличие в туристической отрасли Республики Алтай множества архитектурных форм и элементов традиционной культуры. Например, речь идет о воспроизводстве традиционных жилищ - аилов и юрт, порой в нетрадиционных материалах, однако с сохранением основных формообразующих составляющих; часто встречаются коновязи, смысловая компонента которых носит многогранный характер; порой формы традиционной культуры алтайцев воспроизводятся фрагментарно или стилизованно. Подобного рода примеры часто встречаются на туристических базах, расположенных на территории Республики Алтай, особенно вдоль реки Катунь. Аналогичные практики встречаются и в других субъектах Российской Федерации. Например, «Малые Корелы»- один из лучших музеев деревянного зодчества в Архангельской области. На территории площадью в 140 гектар расположено более 100 деревянных строений. Другой пример - этнопарк «Ватан» в Республике Башкортостан, демонстрирующий особенности быта народов Башкирии. Также следует упомянуть этнопарк «Золотая Орда» в Иркутской области, в поселке Усть-Ордынский, по дороге на озеро Байкал. Известен российский сельский этнопарк, расположенный в селе Зоркальцево «Околица» Томской области, содержащий ряд примеров деревянного зодчества Сибири. На территории другого парка - «Этномир» в Калужской области, расположено множество этнодворов. Представляет интерес этнопарк недалеко от г. Новосибирска «Территория Сибири», где можно увидеть юрту кочевников, чукотскую ярангу, зимовье таежных охотников и т. д. Кроме того, следует упомянуть и фактор общемирового распространения данных практик, которые во многом стали средством самопозиционирования, популяризации, экономической и культурной привлекательности целых регионов на планете, тем самым обеспечивая работу представителям проживающих на определенных территориях этносов.

При этом в рассматриваемых практиках можно выделить как положительные, так и несколько настораживающие тенденции. С одной стороны, они призваны способствовать росту этнокультурной грамотности потребителей туристического сектора, популяризации этнокультурного многообразия и традиций. С другой стороны, уровень грамотности в реализации некоторых практик, особенно в сфере «стихийного» туристического бизнеса, нередко носит поверхностный и усредненный характер, что сказывается отрицательно как на потребителях, так и на регионах, позиционирующих свою культуру, ориентируясь исключительно на туристический спрос, порой выраженный направленности на легкодоступную, простую и узнаваемую продукцию. 
Как итог необходимо отметить определенную противоречивость рассмотренного феномена. Так, среди критических мнений относительно изучаемого явления необходимо отметить искажение ландшафта определенных туристически-востребованных территорий, вследствие размещения на них памятников из других историко-культурных зон и эпох; на феномен историко-культурной эклектичности туристических мест, нередко «подогреваемый» подобными репликами; и, наконец, на преобладающий фактор «больших дистанций» между оригиналами и их копиями, а также на низкий уровень грамотности в выполнении многих стилизаций, порой граничащих с китчем.

В свою очередь, выявляя положительные стороны данного явления, следует указать на провоцируемый им рост разнообразия туристических форм и образов в определенных локациях, на повышение рекреационно-досугового и развлекательного потенциала отрасли, на усиление локаций со слабым туристическим потенциалом. Значимым стимулом к созданию архитектурных копий и стилизаций является проблема сохранности историко-архитектурного наследия, эксплуатация которого в современных условиях нередко приобретает угрожающий для ценных артефактов характер. Памятники архитектуры, представляющие интерес для туристического сектора, переносят на себе множество реставраций и реконструкций; кроме того, они нередко становятся объектами вандализма и неграмотного поведения туристов. Показательным в данном случае является размещение скульптурных копий в Летнем саду и дворцово-парковых ансамблях Санкт-Петербурга, позволившее укрыть подлинники от «агрессивного» воздействия окружающей среды, а также от некорректного поведения туристов. Интересен опыт французов в отношении сохранения пещеры Шове, обнаруженной в 1994 г. и содержащей следы присутствия людей, датируемые сроком в 37000 лет. В пещере обнаружено 435 рисунков с изображениями животных, самым ранним из которых 36000 лет. Живопись пещеры является одной из древнейших в мире. В целях сохранности уникального объекта, являющегося частью Всемирного наследия, в 2015 г. была открыта точная копия пещеры, на создание которой было потрачено несколько лет упорного труда и 55 миллионов евро. Указанный опыт репликаций памятников вполне оправдан и способствует сохранности ценных объектов культурного наследия [3, 4]. И все же весомая часть архитектурных копий и стилизаций, создаваемых в туристической отрасли, в большинстве случаев далека от оригиналов и прототипов и являет собой, скорее, «поверхностную игру» с историко-культурными мотивами. Не стоит также забывать, что в современных условиях туризм представляется полем для глобального межкультурного диалога и позиционирования образов, смыслов и форм других культур, которые могут смешиваться в отдельных локациях, дополнять друг друга и взаимодействовать, - что выражено, в том числе, и в рассматриваемом феномене. В таком ракурсе туризм, обеспечивая широкие возможности культурно-познавательной деятельности, способствует взаимодействию культур, диалогу между ними, а также устойчивому развитию социумов, обладающих широкими рекреационными возможностями.

\section{Список литературы}

1. Эко, У. Инновация и повторение. Между эстетикой модерна и постмодерна // Философия эпохи постмодерна : [сб.]. - Минск : Красико-принт, 1996. - С. 48-73.

2. 17 копий известных мест, построенных в Китае/ [Мастерок.жж.рф] : [аккаунт владельца блога] // “Живой Журнал» = "LiveJournal” : блог-платформа. - 1999-2020. - URL: https://masteroklivejournal-com.turbopages.org/masterok.livejournal.com/s/3483654.html (дата обращения: 25.10.2020).

3. Леонов, И. В. «Новодел» в практике сохранения культурного наследия: границы применения / И. В. Леонов, О.В.Прокуденкова // Вестник Санкт-Петербургского государственного университета культуры и искусств. - 2017. - № 4. - С. 81-84.

4. Леонов И. В. Новодел как форма воспроизведения старины в современной культуре / И. В. Леонов, О. В. Прокуденкова // Вестник Санкт-Петербургского государственного университета культуры и искусств. 2018. - № 1. - С. 145-150. 
Yulia S. Ananeva, Ph. D. in Chemistry Altai State Pedagogical University (Barnaul, Russia) isan1963@yandex.ru

Anastasia G. Zharkova

Polzunov Altai State Technical University (Barnaul, Russia) madsheart@gmail.com

\title{
ARCHITECTURAL COPIES AND IMITATIONS OF HISTORICAL CULTURAL STYLES IN TOURISM INDUSTRY
}

\begin{abstract}
The paper considers factors of increased popularity of making replications of architectural objects found world-known monuments of historical and cultural heritage that attract constant tourists' interest. In witness of their views, the authors point out on many cases in Russian and foreign practices when copies of erected constructions gained international fame in varying degrees of accuracy embody bright features of architectural traditions of one or another culture, its compositional methods, artistic styles and motifs. Also, the paper briefly describes major tendencies of copying architectural examples of traditional cultures within the frames of infrastructural development of Russian touristic sites, discloses key arguments of supporters and opponents of this trend line in the touristic sector.
\end{abstract}

Keywords: tourism, architecture, an artifact, a monument, copy, imitation of a historical cultural style, cultural globalization. 